\title{
The Experience of Ethical Dilemmas, Burnout, and Stress Among Practicing Counselors
}

Patrick R. Mullen

College of William and Mary, prmullen@wm.edu

Carson Morris

Mary Lord

Follow this and additional works at: https://scholarworks.wm.edu/aspubs

\section{Recommended Citation}

Mullen, Patrick R.; Morris, Carson; and Lord, Mary, The Experience of Ethical Dilemmas, Burnout, and Stress Among Practicing Counselors (2017). COUNSELING AND VALUES, 62(1).

10.1002/cvj. 12048

This Article is brought to you for free and open access by the Arts and Sciences at W\&M ScholarWorks. It has been accepted for inclusion in Arts \& Sciences Articles by an authorized administrator of W\&M ScholarWorks. For more information, please contact scholarworks@wm.edu. 


\title{
Research
}

\section{The Experience of Ethical Dilemmas, Burnout, and Stress Among Practicing Counselors}

\begin{abstract}
Patrick R. Mullen, Carson Morris, and Mary Lord
The authors reported findings from a correlational investigation examining the relationship between counselors' $(N=140)$ experiences with ethical dilemmas and their reported levels of burnout and stress. Using structural equation modeling, the authors identified that a higher rate of encountering ethical dilemmas related to an increased level of counselor burnout and stress among the participants. However, higher rates of reflecting on the ethical dilemmas did not have a relationship with participants' burnout and stress. The authors present implications of these findings for counselors, along with future research directions.
\end{abstract}

Keywords: ethical dilemmas, burnout, stress, practicing counselors

7

he counseling field is rich with ethical issues (American Counseling Association [ACA], 2014; Bodenhorn, 2006; Herlihy \& Dufrene, 2011), so counselors have to be knowledgeable about current ethical and legal topics and attentive to their day-to-day clinical work. Ethical dilemmas are "problems for which no choice seems completely satisfactory, since there are good, but contradictory reasons to take conflicting and incompatible courses of action" (Kitchener, 2000, p. 2). Ethical standards or codes of ethics (ACA, 2014; National Board for Certified Counselors, 2012) exist to provide a road map for counselors to abide by when they face ethical challenges. In addition, counselors use decision-making models (i.e., Cottone \& Claus, 2000; Kocet \& Herlihy, 2014; Levitt \& Aligo, 2013; Luke, Goodrich, \& Gilbride, 2013), which incorporate ethical standards, moral principles, and cultural values to help resolve ethical dilemmas as they arise. However, ethical

Patrick R. Mullen, Carson Morris, and Mary Lord, Department of Interdisciplinary Professions, East Carolina University. Patrick R. Mullen is now at Department of School Psychology and Counselor Education, College of William \& Mary. Correspondence concerning this article should be addressed to Patrick R. Mullen, Department of School Psychology and Counselor Education, College of William \& Mary, PO Box 8795, Williamsburg, VA 23188 (e-mail: prmullen@wm.edu). 
dilemmas can differ in type and severity of issues (Bodenhorn, 2006; Herlihy \& Dufrene, 2011), ranging from the use of social media with clients (Jordan et al., 2014; Mullen, Griffith, Greene, \& Lambie, 2014) to reporting suspected abuse (Henderson, 2013; Lambie, 2005). Therefore, the navigation of ethical issues necessitates that counselors are observant to the content of their situations, have a sound knowledge of the literature on ethics in counseling, and hold the ability to make sound ethical decisions (Lambie, Hagedorn, \& Ieva, 2010). The multitude of potential ethical issues and knowledge required to make effective decisions can be perplexing for counselors.

Ethical decision making is a process that is multidimensional and often complex (Levitt, Farry, \& Mazzarella, 2015). Often, issues of an ethical nature force counselors to test their knowledge and understanding of key topics, including reflection on their own personal values and their role in counseling (Levitt \& Hartwig Moorhead, 2013). In addition, ethical issues are emerging and changing (Herlihy \& Dufrene, 2011), and ethical codes are routinely revised (e.g., ACA, 2014). Therefore, on the basis of the fluidity of possible ethical dilemmas, it is logical that counselors experience difficulties when confronting ethical dilemmas because of the need to stay current with trends in counseling.

An additional aspect that adds to the complexity is counselors' experiences with and reflection on difficult ethical situations that may lead to emotional distress. For example, some ethical situations may involve circumstances that are emotionally taxing to the counselor, such as reporting abuse or neglect of a minor (Henderson, 2013; Lambie, 2005). Although there is limited literature on counselors' emotional experience of ethical dilemmas, authors have described the negative cost of caring for clients in literature on secondary traumatic stress (Figley, 2002; Stamm, 2010) and empathy fatigue (Stebnicki, 2008). Stebnicki (2008) noted that being empathetic requires counselors "to respond to and even experience vicariously the client's pain and suffering" (p. 3), which can lead to decreased concern for clients and impaired well-being for the counselor. Furthermore, secondary traumatic stress manifests as the negative emotional response, such as fear, difficulty sleeping, and intrusive images, which counselors endure as a result of secondhand exposure to traumatic events experienced by clients (Figley, 2002; Stamm, 2010). These emotionally taxing experiences lead to collateral and undesirable emotional responses that can cause counselor impairment (ACA, 2014; Maslach, 2003; Stamm, 2010; Stebnicki, 2008), along with a diminished ability to complete job roles effectively and a heightened likelihood of harming clients (Figley, 2002; Lawson, 2007). One protective factor for counselors who experience negative affective responses as a result of their client's situation is self-reflection.

Self-reflection is addressed early in counselor training (Young, 2013). Self-reflection includes an enhanced understanding and awareness of one's internal thought process and reactions (Hill \& Lent, 2006), and is central to counselor development (Griffith \& Frieden, 2000; Skovholt \& Ronnestad, 1992). Specifically, self-reflection is associated with observing and interpreting 
one's actions and insights, and, in turn, promotes one to take control over his or her own thinking and decision making (Pompeo \& Levitt, 2014; Von Wright, 1992). Self-reflection allows a person to gather information regarding the intention of an action and to consider his or her place in the decisionmaking process. As Pompeo and Levitt (2014) noted, self-reflection is also vital in the ethical decision-making process because it leads to self-awareness about one's own values and perspective. For example, when encountering ethical dilemmas, counselors can reflect on their own values and how these values affect their thought process. Then, counselors can use their insights to make a decision that is free of bias or misdirection. Researchers have made the case that self-reflection generates greater self-awareness and insight that leads to better clinical outcomes for clients (Anderson \& Levitt, 2015; Chao, 2012). The awareness that is achieved through self-reflection is also a protective factor preventing counselors from experiencing compassion fatigue or burnout (Merriman, 2015).

Limited literature was identified exploring the relationship between counselors' self-reflection, reflection on ethical dilemmas, stress, and burnout. However, Venart, Vassos, and Pitcher-Heft (2007) suggested that self-awareness achieved through self-reflection is a valuable strategy to catch warning signs of personal distress. Lawson (2007) found that counselors who valued selfawareness were also more satisfied with their jobs. In addition, Giacalone, Jurkiewicz, and Promislo (2016) found that among business professionals, the amount of consideration or reflection on moral issues (i.e., reflective moral attentiveness; Reynolds, 2008) was positively associated with measures of well-being (hope, happiness, and personal growth initiative). We believe the occurrence of ethical dilemmas in counseling is a distinct source of stress and burnout for counselors, similar to secondary traumatic stress and empathy fatigue. Also, counselors reflect on the ethical situations they encounter (ACA, 2014; Pompeo \& Levitt, 2014), which can be a protective factor against burnout and stress (Giacalone et al., 2016; Merriman, 2015; Venart et al., 2007).

Research on the relationship between counselors' experiences of ethical issues and their stress and burnout is sparse. Therefore, we examined the theoretical framework of stress and burnout as a means to support a logical connection with counselors' experiences of ethical dilemmas. Stress is a construct that has a long history in the literature, dating as far back as the 1930s (Selye, 1936). Selye (1980) described stress broadly by coining it as "the nonspecific response of the body to any demand" (p. 127). Scholars developed a variety of definitions of stress (Ivancevich \& Matteson, 1980; Janis \& Mann, 1977; McGrath, 1976). Often, the definition of stress used by researchers is determined by the research question under investigation (Parker \& DeCotiis, 1983), yet scholars have predominantly used Lazarus and Folkman's (1984) articulation of stress (Driskell \& Salas, 1996; Lazarus, 2006).

In the Transactional Model of Stress and Coping, Lazarus and Folkman (1984) described the experience of stress as the processes of appraisal and 
coping. Specifically, stress is defined as a "particular relationship between the person and the environment that is appraised by the person as taxing or exceeding his or her resources and endangering his or her well-being" (Lazarus \& Folkman, 1984, p. 19). Appraisal is the process by which a person understands and makes meaning of an event or stressor (i.e., the demand placed on an individual because of internal or external environmental factors; Lazarus \& Cohen, 1977). Appraisal includes three separate processes: primary appraisal, secondary appraisal, and reappraisal (Lazarus \& Folkman, 1984). Primary appraisal is the process in which individuals determine if the stress is going to affect them. For example, individuals evaluate whether an encounter is irrelevant, stressful, or beneficial to their or another's well-being. Folkman, Lazarus, Gruen, and DeLongis (1986) noted that individuals have values, goals, and beliefs that influence the relevance of a stressor to their well-being. Secondary appraisal is the process in which individuals determine how they can overcome or cope with the challenge (Lazarus \& Folkman, 1984). Reappraisal represents a modified appraisal that is the result of new information from the environment, and may increase or decrease the stress one undergoes (Lazarus \& Folkman, 1984).

The process of coping is an individual's cognitive and behavioral effort to respond to internal and external demands (Lazarus \& Folkman, 1984). Coping occurs when the person-environment transactions are deemed strenuous or exceed an individual's resources. As Folkman and Moskowitz (2004) noted, there are three main functions of coping: (a) dealing with the problems that created the stress (problem-focused coping), (b) managing emotions related to stress (emotion-focused coping), and (c) managing the meaning of a situation (meaning-focused coping). When individuals are confronted with stressful events that are greater than the resources they have to manage the stress, they cope by using one of these coping functions. If individuals are unable to cope with a stressful event, they incur a higher negative experience (higher stress).

As counselors encounter ethical dilemmas, they come across situations that vary in severity (e.g., easy or difficult to determine appropriate direction; Bodenhorn, 2006; Herlihy \& Dufrene, 2011). Moreover, ethical situations may vary in emotional difficulty (e.g., no emotional reaction, significant emotional reaction), which can lead to negative vicarious experiences (Figley, 2002; Stamm, 2010; Stebnicki, 2008). Counselors' ability to resolve ethical dilemmas effectively is likely based on their level of ethical knowledge and moral development (Lambie et al., 2010), along with their level of ethical and legal self-efficacy (Mullen, Lambie, \& Conley, 2014; Mullen, Lambie, Griffith, \& Sherrell, 2016) and decision-making ability (Dufrene \& Glosoff, 2004). In addition, the stress and burnout experienced as a result of ethical situations is probably associated with the counselors' demographic and setting characteristics (Lent \& Schwartz, 2012; Thompson, Amatea, \& Thompson, 2014), such as clinical setting and experience as a counselor. Even so, as counselors encounter difficult ethical situations (stressors) in which they 
do not have the resources (coping ability) to manage, they likely experience stress. Furthermore, it is logical that the higher occurrence of ethical dilemmas (stressors) relates to higher levels of stress.

In addition, we believe that counselors' experiences with ethical dilemmas relate to their level of burnout. The construct of burnout has been researched across many disciplines (Maslach, Schaufeli, \& Leiter, 2001; Schaufeli, Leiter, \& Maslach, 2009) and dates back to the early 1970s (Freudenberger, 1974; Maslach, 1976). Freudenberger (1974, 1986) first thought burnout resulted from feeling exhausted and overwhelmed as a result of dealing with the concerns of others. Pines and Maslach (1978) further developed the definition of burnout as "physical and emotional exhaustion, involving the development of negative self-concept, negative job attitude, and loss of concern and feelings for clients" (p. 234). Traditionally, burnout involves feelings of being emotionally drained, ineffective, and less fulfilled by work-related tasks (Maslach, 2003; Maslach et al., 2001; Stamm, 2010).

For this investigation, we used Lee et al.'s (2007) model of counselor burnout. Lee and colleagues articulated a novel construct of counselor burnout that they considered to be "the failure to perform clinical tasks appropriately because of personal discouragement, apathy to symptom stress, and emotional/physical harm" (p. 143). They also stated that counselor burnout consists of the domains of exhaustion, negative work environment, devaluing clients, incompetence, and deterioration in personal life. They found that the domains of counselor burnout, as measured by the Counselor Burnout Inventory (CBI; Lee et al., 2007), correlated with factors measured by the Maslach Burnout Inventory (Maslach \& Jackson, 1981). Scholars have also noted that the chronic exposure to stress or stressful circumstances leads to burnout (Maslach, 2003; Maslach et al., 2001; Schaufeli \& Enzmann, 1998; Schaufeli et al., 2009).

\section{The Current Study}

Ethical issues are inherent in the counseling profession (i.e., ACA, 2014), and counselors encounter ethical issues on a regular basis over the course of their careers (Remley \& Herlihy, 2013). The occurrence and difficulty of ethical issues vary (Bodenhorn, 2006), requiring counselors to resolve complex and multifaceted problems (Lambie et al., 2010; Levitt et al., 2015). Furthermore, stress is the product of individuals' appraisal of the demands of a difficult situation and their ability to cope with or resolve the difficulty (Lazarus, 2006; Lazarus \& Folkman, 1984), whereas burnout results from the chronic exposure to a taxing and emotionally demanding work environment (Cordes \& Dougherty, 1993; Maslach, 2003; Schaufeli \& Enzmann, 1998; Schaufeli et al., 2009). At the time of this study, there was no research examining the relationship between counselors' experiences of ethical dilemmas and their stress and burnout. Therefore, we explored the following research question: "Do practicing 
counselors' observation of ethical issues (source of stress) and reflection upon ethical issues (protective factor) relate to their degree of burnout and stress?" We hypothesized that counselors who observe ethical issues at a higher frequency have a greater likelihood of experiencing burnout and stress and counselors who reflect on ethical dilemmas at a higher rate have less likelihood of experiencing burnout and stress. We also hypothesized that counselors' level of stress will correlate with their level of burnout.

\section{Method}

\section{Participants and Procedure}

Before beginning this study, we obtained approval from the institutional review board at our university. To obtain a sample of practicing counselors, we used several strategies. First, we randomly identified four states (Arizona, Colorado, Connecticut, and Florida) within the United States. Then, we obtained the public databases of licensed counselors for each state through their respective licensure/health boards. For each state, we selected 100 participants from a list of all the licensed counselors in the state using simple random sampling. In total, we selected 400 participants to invite to complete the study materials.

Individuals were invited to participate in this study through a three-step, paper-based mail process that was an adaptation of the tailored design method (Dillman, Smyth, \& Christian, 2009). The first mail out included a letter describing the study, the study materials (instruments and consent form), and a stamped return envelope. The second mail out was a reminder postcard. The third mail out was another letter with a final invitation to complete the survey, the survey materials, and a stamped return envelope. There was no incentive used in this investigation. Of the 400 participants that received an invitation to participate, 140 completed and returned a survey packet (35\% usable response rate). Table 1 presents the participants' demographic characteristics.

\section{Instruments}

We used three instruments to explore the research question for this study. The data collection instruments included (a) the CBI (Lee et al., 2007), (b) the Perceived Stress Scale (PSS; Cohen, Kamarck, \& Mermelstein, 1983), and (c) the Moral Attentiveness Scale (MAS; Reynolds, 2008). In addition, we developed a demographics form to capture the participants' general information.

$C B I$. In this study, we used the CBI to examine the degree of burnout experienced by the participants. The CBI is a 20-item self-report scale that uses a Likert-type scale ranging from 1 (never true) to 5 (always true). The 
TABLE 1

Participant Characteristics

\begin{tabular}{|c|c|c|}
\hline Variable & $\%$ & $n$ \\
\hline \multicolumn{3}{|l|}{ Age } \\
\hline $20-29$ & 1.4 & 2 \\
\hline $30-39$ & 22.1 & 31 \\
\hline $40-49$ & 22.9 & 32 \\
\hline $50-59$ & 20.0 & 28 \\
\hline $60-69$ & 28.6 & 40 \\
\hline $70+$ & 5.0 & 7 \\
\hline \multicolumn{3}{|l|}{ Years of experience } \\
\hline $0-9$ & 35.0 & 49 \\
\hline $10-19$ & 32.9 & 46 \\
\hline $20-29$ & 17.1 & 24 \\
\hline $30-39$ & 12.9 & 18 \\
\hline $40+$ & 2.1 & 3 \\
\hline \multicolumn{3}{|l|}{ Ethnicity } \\
\hline African American & 4.3 & 6 \\
\hline Asian American & 2.1 & 3 \\
\hline Hispanic American & 6.4 & 9 \\
\hline Multiracial & 2.1 & 3 \\
\hline Native American & 0.7 & 1 \\
\hline White (non-Hispanic) & 82.9 & 116 \\
\hline Other & 1.4 & 2 \\
\hline \multicolumn{3}{|l|}{ Gender } \\
\hline Female & 75.0 & 105 \\
\hline Male & 24.3 & 34 \\
\hline Other & 0.7 & 1 \\
\hline \multicolumn{3}{|l|}{ Primary professional identity } \\
\hline Addictions counselor & 0.7 & 1 \\
\hline Marriage and family therapist & 3.6 & 5 \\
\hline Mental health counselor/licensed professional counselor & 82.1 & 115 \\
\hline Other & 21.1 & 17 \\
\hline Professional school counselor & 1.4 & 2 \\
\hline
\end{tabular}

Note. $N=140$.

CBI measures five dimensions of burnout across five subscales: Exhaustion, Incompetence, Negative Work Environment, Devaluing Client, and Deterioration in Personal Life. Sample items from the CBI include "I have little empathy for my clients," "I feel negative energy from my supervisor," and "I feel I am an incompetent counselor." Higher scores for each of the subscales represented a higher degree of the respective dimension of burnout.

Lee and colleagues (2007) evidenced the construct validity of the CBI through an exploratory factor analysis that revealed a five-factor solution. Furthermore, Lee et al. (2007) performed a confirmatory factor analysis (CFA) with an adequate fit to the data that reinforced a five-factor model. The Cronbach's alphas of the domain subscales indicated good internal consistency, with scores ranging from .80 to .86 for Exhaustion, .73 to .81 for Incompetence, .83 to .85 for Negative Work Environment, .61 to .83 for Devaluing Client, and .67 to .84 for Deterioration in Personal Life (Lee et 
al., 2007; Lee, Cho, Kissinger, \& Ogle, 2010; Puig et al., 2012). With the data from this study, the Exhaustion $(\alpha=.90)$, Negative Work Environment $(\alpha=$ $.86)$, and Deterioration in Personal Life $(\alpha=.81)$ subscales produced good internal consistency, whereas the Incompetence $(\alpha=.76)$ and Devaluing Client $(\alpha=.70)$ subscales produced acceptable internal consistency.

PSS. We used the PSS to measure the participants' degree of stress. The PSS is a 10-item self-report measure that uses a Likert-type scale ranging from 0 (never) to 4 (very often). The PSS is a one-dimensional measure that asks participants to report on their perception of stress over the past 30 days. Sample items from the PSS include "In the last month, how often have you felt nervous and stressed?" "In the last month, how often have you felt that things were going your way?" (reverse coded), and "In the last month, how often have you felt difficulties were piling up so high that you could not overcome them?" Higher scores on the PSS indicate a higher degree of stress. The PSS has had good internal consistency in previous research, with Cronbach's alphas ranging from .84 to .91 (Chao, 2011; Cohen et al., 1983; Daire, Dominguez, Carlson, \& Case-Pease, 2014; Mullen \& Gutierrez, 2016). The Cronbach's alpha for the PSS scores with the data in this study was .82, which indicated good internal consistency.

MAS. We used the MAS to examine participants' experiences with ethical dilemmas in their work as counselors. Reynolds (2008) defined moral attentiveness as the degree to which people perceive or observe and reflect on moral issues and aspects of morality in their day-to-day experiences. The MAS is a 12-item self-report measure that uses a Likert scale ranging from 1 (strongly disagree) to 7 (strongly agree). The MAS has two subscales: Perceptual Moral Attentiveness and Reflective Moral Attentiveness. Perceptual moral attentiveness is defined as the degree to which a person observes and recognizes moral issues in day-to-day activities, whereas reflective moral attentiveness is defined as the degree to which a person considers or reflects on moral issues (Reynolds, 2008). Although the title of the MAS reflects moral issues, we selected this scale because the subscales and items examine the constructs desired for our investigation. For example, items from the Perceptual Moral Attentiveness subscale include "In a typical day, I face several ethical dilemmas," "I rarely face ethical dilemmas" (reverse coded), and "I regularly face decisions that have significant ethical implications." In addition, sample items from the Reflective Moral Attentiveness subscale include "I like to think about ethics," "I often find myself pondering about ethical issues," and "I often reflect on the moral aspects of my decisions." We summed all of the items on each subscale to calculate their respective total scores. Higher scores on the Perceptual Moral Attentiveness subscale represented participants' higher occurrence of observing moral or ethical issues, whereas higher scores on the Reflective Moral Attentiveness subscale represented participants' higher occurrence of reflecting on the moral or ethical issues they encounter. 
Reynolds (2008) found that perceptual moral attentiveness correlated with participant's self-report of moral behavior $(r=.21, p<.01 ; n=242)$ and reflective moral attentiveness correlated with a measure of moral awareness $(r=$ $.32, p<.01 ; n=159$ ). In previous research, Giacalone et al. (2016) found that the Perceptual Moral Attentiveness subscale had good internal consistency, with a Cronbach's alpha reliability coefficient of .90, and the Reflective Moral Attentiveness subscale had good internal consistency, with a Cronbach's alpha reliability coefficient of .87. Reynolds (2008) also found both subscales to have internal consistency, with a Cronbach's alpha reliability coefficient of .87 for the Perceptual Moral Attentiveness and .84 for the Reflective Moral Attentiveness subscales. The Perceptual Moral Attentiveness $(\alpha=.87)$ and Reflective Moral Attentiveness $(\alpha=.94)$ subscales produced good internal consistency with the data from our study.

Results

We screened the data before we applied analysis procedures. In total, 140 completed survey packets were returned by participants. After transferring the data into SPSS (Version 20), we found two cases with at least one variable that had an extreme outlier (data points three or more standard deviations from the mean) using converted $z$ scores (Osborne, 2012). To address these outliers, we used a Winsorized mean using adjacent data points (Barnett \& Lewis, 1994; Osborne \& Overbay, 2004). We then examined the data to test the assumptions related to structural equation modeling (SEM; normality and multicollinearity; Hair, Black, Babin, Anderson, \& Tatham, 2006; Tabachnick \& Fidell, 2007), and no violations were identified. Table 2 presents the means, standard deviations, and correlations of the variables in this study.

Before data analysis, we also examined the appropriateness of the sample size acquired in this study for the use of SEM. Bentler and Chou (1987)

\section{TABLE 2}

\section{Means, Standard Deviations, and Correlations of the Variables}

\begin{tabular}{|c|c|c|c|c|c|c|c|c|c|c|}
\hline Variable & $M$ & $S D$ & 1 & 2 & 3 & 4 & 5 & 6 & 7 & 8 \\
\hline 1. Exhaustion & 2.52 & 0.09 & - & & & & & & & \\
\hline 2. Incompetence & 2.03 & 0.63 & $.50^{*}$ & - & & & & & & \\
\hline 3. Negative work & & & & & & & & & & \\
\hline environment & 2.02 & 0.94 & $.60^{*}$ & $.42^{*}$ & - & & & & & \\
\hline $\begin{array}{l}\text { 4. Devaluing client } \\
\text { 5. Deterioration in }\end{array}$ & 1.42 & 0.46 & $.40^{*}$ & $.50^{*}$ & $.37^{*}$ & - & & & & \\
\hline personal life & 2.17 & 0.80 & $.70^{*}$ & $.45^{*}$ & $.52^{*}$ & $.34^{*}$ & - & & & \\
\hline 6. Stress & 1.35 & 0.50 & $.61^{*}$ & $.39^{*}$ & $.49^{*}$ & $.35^{\star}$ & $.56^{*}$ & - & & \\
\hline $\begin{array}{l}\text { 7. Perceptual moral } \\
\text { attentiveness } \\
\text { 8. Reflective moral }\end{array}$ & 3.18 & 1.20 & $.42^{*}$ & $.28^{*}$ & $.31^{*}$ & $.25^{\star}$ & $.41^{*}$ & $.36^{*}$ & - & \\
\hline attentiveness & 4.39 & 1.33 & $.23^{*}$ & .07 & .07 & .07 & $.34^{*}$ & $.25^{\star}$ & $.58^{*}$ & - \\
\hline
\end{tabular}

Note. $N=140$.

${ }^{*} p<.001$. 
recommended 10 cases to every free parameter, and Nunnally (1967) recommended 10 cases to every variable as a rule of thumb. More recently, Jackson (2003) and Kline (2011) recommended a ratio of 20:1 (cases/estimated parameters) as ideal and a 10:1 ratio as acceptable, with any ratio below 10:1 as unacceptable. The SEM model tested in this investigation included 10 estimated parameters, which requires a minimum sample size of 100 , with a sample of 200 as being ideal. Our data collection methods returned a sample of 140, which is acceptable for SEM given the simplicity of our model and in light of Jackson's and Kline's recommendation.

\section{Model Testing}

In this study, we used a two-step SEM method (Kline, 2011) as an approach to test the research hypothesis. We selected SEM for this investigation because it is a sophisticated collection of correlational analysis techniques that combines the use of regression analysis and CFA to test a hypothesized directional relationship (Gall, Gall, \& Borg, 2007; Tabachnick \& Fidell, 2007). The first step in the SEM testing was to complete a CFA to inspect the measurement model for each latent variable. For this study, the CFA represented the construct of burnout (CBI; Lee et al., 2007) and its fit with the data. The second step in SEM was to test the structural model. The structural model examined the hypothesized relationships among the variables under investigation, which, in this study, included burnout, stress, perceptual moral attentiveness, and reflective moral attentiveness.

The measurement model and structural model were evaluated based on standardized factor loadings and model fit indices (Byrne, 2010; Kline, 2011). All standardized factor loadings should be significant (i.e., .40 or higher) to be considered acceptable (Byrne, 2010; Kline, 2011; Stevens, 1992). To examine the fit of the CFA and SEM, we used several recommended fit indices (see Hu \& Bentler, 1999; Kline, 2011; Weston \& Gore, 2006). The fit indices included (a) chi-square (nonsignificance indicates fit), (b) comparative fit index (CFI; $\geq .95$ indicates fit), (c) goodness-of-fit index (GFI; $\geq .90$ indicates fit), (d) standardized root-mean-square residual (SRMR; $\leq .06$ indicates fit), and (e) root-mean-square error of approximation (RMSEA; $\leq .10$ indicates fit). Modifications were made to the model if needed. We applied a maximum likelihood estimation technique for the CFA and SEM.

\section{Measurement Model}

We used a CFA to examine the latent variable representing burnout to test whether it would be appropriate for use in this SEM. To be acceptable for use in the SEM, the CFA should produce fit indices within the cutoff range and should have acceptable standardized factor loadings. We totaled each of the five subscales on the CBI, which represent the different dimensions of counselor burnout, to create composite scores. These composite scores 
contribute to the latent variable of burnout. The measurement model for burnout resulted in acceptable standardized factor loadings ranging from .50 to .87. The fit indices for the measurement model were all acceptable except for $\operatorname{RMSEA}, \chi^{2}(5, N=140)=15.01, p=.01 ; \mathrm{GFI}=.96$; $\mathrm{CFI}=.96$; $\mathrm{RMSEA}=$ .12 ; SRMR $=.05$.

We consulted the modification indices and the standardized residual covariance matrix (Byrne, 2010; Kline, 2011), and they suggested the correlation of the error terms for the composite scores of devaluing client and incompetence. However, after reviewing the scale items and the literature (see Lee et al., 2007), we found that a theoretical connection between these constructs was not justifiable; therefore, these items were not correlated (Byrne, 2010). The RMSEA fit index was not acceptable for the measurement model; however, RMSEA can be large and sometimes unsuitable for models with small degrees of freedom (Kenny, Kaniskan, \& McCoach, 2015). On the basis of the model fit indices and standardized factor loadings, we deemed the CBI measurement model acceptable for use in the structural model despite the poor RMSEA fit index.

\section{Structural Model}

We developed the structural model (see Figure 1) based on a review of the literature on counselor burnout, stress, and ethical dilemmas. We used the measurement model of burnout (CBI; Lee et al., 2007) as a latent variable and the composite scores of the PSS (perceived stress; Cohen et al., 1983) and the MAS (perceptual and reflective moral attentiveness; Reynolds, 2008) as observed variables. Perceptual moral attentiveness and reflective moral

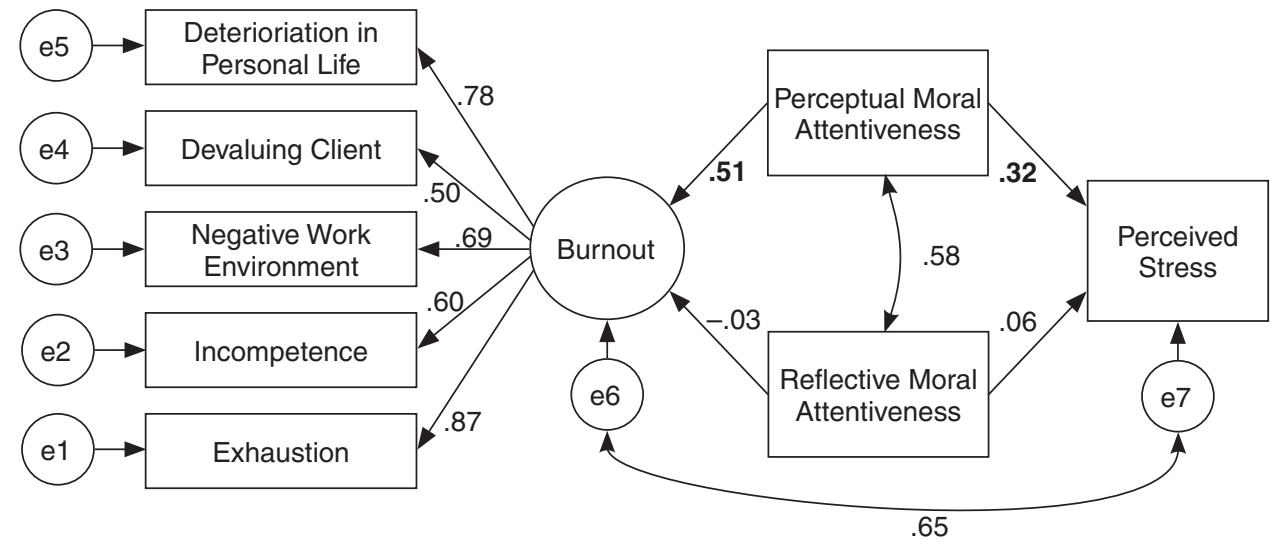

FIGURE 1

\section{Structural Model}

Note. Bold values indicate statistically significant standardized regression weights; e1-e7 represent error variance. 
attentiveness were exogenous variables (independent variables), whereas burnout and perceived stress were endogenous variables (dependent variables) within this structural model. In addition, the error terms for burnout and perceived stress were set to correlate given their theoretical connection (Maslach, 2003; Schaufeli \& Enzmann, 1998; Schaufeli et al., 2009), and perceptual and reflective moral attentiveness were set to correlate based on previous research (Reynolds, 2008).

An examination of the structural model indicated an acceptable goodness of fit for all fit indices with these data, $\chi^{2}(17, N=140)=29.12, p=.03$; GFI = $.95 ; \mathrm{CFI}=.97$; RMSEA $=.07 ; \mathrm{SRMR}=.05$. Inspection of the standardized factor loadings indicated that counselors' perceptual moral attentiveness predicted $26 \%(\beta=.51, p<.001$; large effect size; Sink \& Stroh, 2006) of the variance in burnout scores and 10\% $(\beta=.32, p<.001$; medium effect size; Sink \& Stroh, 2006) of the variance in their perceived stress scores. However, review of the standardized factor loadings indicated that counselors' reflective moral attentiveness did not relate to the variance in burnout $(\beta=-.03, p=.74)$ or perceived stress $(\beta=.06, p=.53)$ scores. We found a strong positive correlation for burnout and perceived stress $(r=.65, p<.001)$ and for perceptual moral attentiveness and reflective moral attentiveness $(r=.58, p<.001)$. The CBI subscales Deterioration in Personal Life $(\beta=.78)$ and Exhaustion $(\beta=$ .87) were the strongest factors of burnout, followed by the Devaluing Client $(\beta=.50)$, Incompetence $(\beta=.60)$, and Negative Work Environment $(\beta=.69)$ subscales. The SEM results indicated that counselors' observation of ethical issues had a positive relationship to their burnout and stress. These results also indicated that counselors' reflection on ethical issues did not relate to their burnout and stress. Finally, the findings indicated that counselors' stress and burnout had a strong positive correlation.

\section{Discussion}

In this investigation, we examined the relationship between practicing counselors' experiences with ethical dilemmas and their burnout and stress. Specifically, we tested the directional hypothesis that counselors' observation of ethical issues would have a positive relationship with their degree of burnout and stress (see Figure 1). We used the existing literature (Bodenhorn, 2006; Herlihy \& Dufrene, 2011; Lazarus \& Folkman, 1984; Lee et al., 2007) to inform this hypothesis. To date, researchers have not explored the relationship between these constructs among counseling professionals. Participants in this study with higher perceptual moral attentiveness also reported higher levels of burnout. These findings were logical considering that stress is associated with the appraisal and coping of difficult situations (i.e., ethical dilemmas) and that burnout develops because of ongoing negative experiences that are associated with helping people (Maslach, 2003). It is also important to consider that stress and burnout may be a product of many aspects of a counselor's work and that there may be other variables (e.g., 
demographic variables; Lent \& Schwartz, 2012; Thompson et al., 2014) not measured in the study. However, these findings provide a novel framework for which scholars should consider the negative effects of ethical dilemmas.

This investigation also tested the research hypothesis that counselors' level of reflection on ethical issues will have a negative relationship with their degree of burnout and stress. Similar to the first research hypothesis, we used the existing literature (Giacalone et al., 2016; Lazarus \& Folkman, 1984; Lee et al., 2007; Merriman, 2015) to develop this hypothesis. The findings did not support this hypothesis; instead, the findings indicated that counselors' reflectivity toward ethical issues does not relate to their burnout or stress. These findings were surprising considering that counselors are trained to reflect on ethical standards and decision-making models to resolve ethical dilemmas (ACA, 2014; Remley \& Herlihy, 2013). In addition, researchers have found a positive relationship between reflective moral attentiveness and well-being in previous research (Giacalone et al., 2016). However, this finding may highlight that only the occurrence of ethical dilemmas relates to one's stress and burnout, and thinking about the dilemmas does not have this same relationship. Alternatively, this finding may be a reflection of the MAS (Reynolds, 2008), which is a novel measure that may not represent the intended construct of reflection on ethical dilemmas. Another conceptually different measure of counselors' reflective activities related to ethical dilemmas may produce findings that support the protective nature of self-reflection among counselors. Still, the results regarding the lack of relationship between counselors' reflection on ethical issues and their stress and burnout give merit for further research to verify these findings because they contradict previous research (Giacalone et al., 2016).

\section{Implications for Counselors, Counselor Educators, and Clinical Supervisors}

Counselors' professional well-being and avoidance of impairment is an ethical responsibility (ACA, 2014). Also, stress and burnout can lead to counselor impairment, which may result in deteriorated services for clients (Lawson $\&$ Venart, 2005). Thus, counselors should strive to address factors that may contribute to their stress and burnout. We found that counselors who observed higher rates of ethical dilemmas (perceptual moral attentiveness) were more likely to report higher levels of stress and burnout. We believe that these results have implications for counselors' well-being. First, counselors should consider the collateral costs of encountering and managing ethical situations. When counselors encounter an ethical dilemma and resolve the situation, it may be beneficial to also recognize the stress that resulted from this experience. Similarly, when counselors encounter troubling dilemmas, it may be useful to integrate coping strategies into the resolution of the problem. If counselors ignore the emotional response associated with ethical dilemmas, they may experience undue stress and burnout. 
Counselors can seek collegial support through supervision or consultation when facing ethical dilemmas (ACA, 2014; Remley \& Herlihy, 2013). Seeking consultation would not only support their decision-making process but also allow them to reflect on the stress or emotional response that resulted from the situation. In addition, counselors can enact career-sustaining behaviors (see Lawson, 2007; Lawson \& Myers, 2011) or coping skills as a way to manage their own reactions to difficult ethical issues. Career-sustaining behaviors are strategies counselors can use to maintain a healthy level of functioning and a positive attitude about their jobs (Kramen-Kahn \& Hansen, 1998). Lawson (2007) found that career-sustaining behaviors are associated with greater job satisfaction in practicing counselors, and Lawson and Myers (2011) found that counselors who engaged in more career-sustaining behaviors reported higher levels of wellness. Counselors should also be attentive to colleagues who have faced difficult ethical circumstances. If a counselor notices that a colleague has encountered a challenging ethical situation or faces ethical dilemmas at a higher rate, it may be beneficial to bring attention to the stress it is likely causing with the aim to help the peer cope effectively.

Young and Lambie (2007) noted various strategies mental health agencies can use to reduce job stress and promote well-being. One strategy noted by Young and Lambie that may be useful as a means to manage the stress resulting from ethical dilemmas is group supervision. During dedicated group supervision, counselors can reflect on ethical dilemmas that have come up, discuss steps to resolve the dilemmas (if they have not already been resolved), and discuss personal reactions to the issues. Group supervision also allows colleagues to provide social support and discuss ways to cope with stress and burnout related to the ethical dilemma.

As noted by Merriman (2015) and Roach and Young (2007), it is important that counselor education programs prepare trainees to maintain their professional well-being. On the basis of our findings, we believe it is important for educators to teach students how to recognize and manage the stress and burnout that may arise as a result of the ethical issues they face in their work with clients. In an ethics course, counselor educators can use assignments that engage students in learning about ethical dilemmas faced by counselors, and students can reflect on their personal reactions to the dilemmas, along with ways to resolve it. Specifically, counselor educators can have students conduct a face-to-face or telephone interview with a practicing counselor regarding the common and difficult ethical situations they have encountered (Kaczmarek, Barclay, \& Smith, 1996). Then, counselor educators can provide essay prompts and have students write a reflection paper about their personal reactions to the interviews. In addition, counselor educators can lead a class discussion on the results of the students' interviews to identify common ethical dilemmas that could be stressful and effective ways to respond to the stress.

Clinical supervisors can also take measures to help supervisees increase awareness of their reactions to ethical issues. In addition to supervising the 
trainees on how to resolve ethical dilemmas, supervisors can have trainees review their personal or emotional reactions to ethical situations that arise during their clinical experiences. For example, supervisors who use reflective dialogue (Griffith \& Frieden, 2000; Stinchfield, Hill, \& Kleist, 2007) encourage trainees to consider themselves as counselors (increasing self-awareness about response to a stressor) and to focus on skill development (how to resolve the dilemmas and manage the stress). Consequently, clinical supervisors not only model the skills needed to resolve the situation but also bring attention to the stress response that results from a difficult ethical dilemma. Supervisors can subsequently introduce effective strategies (i.e., problem-focused coping) to cope with the stressful experience that may have occurred as a result of the dilemma.

\section{Limitations and Future Research Directions}

This study has several limitations worth noting. First, the sample size in this study was well below what is needed to generalize the result to the population of practicing counselors (Krejcie \& Morgan, 1970). Similarly, the sample size in this study was not ideal for SEM because it may increase the chance for Type II error (Kline, 2011); nevertheless, the sample size was acceptable based on the simplicity of the model and recommendations from the literature (Jackson, 2003; Kline, 2011). The response rate for this study was 35\%, and the results should be considered in light of possible nonresponse bias (Gall at al., 2007). An additional limitation was that we used the MAS, which is a novel measure in counseling research, to measure counselors' experiences with ethical dilemmas. Nevertheless, as Mullen, Lambie, and Conley (2014) noted, there are few measures available for research on counselors' experiences with ethical issues, and this study introduces the MAS as a relevant and innovative measure for future research. In addition, the MAS is the only instrument available to measure the constructs associated with this study. A final noted limitation is that the study was a correlational investigation, which means we cannot claim that ethical dilemmas cause stress and burnout (Gall et al., 2007). Despite these limitations, we provide a fresh lens in which to explore counselors' experiences with ethical dilemmas and the relationship between these experiences and stress and burnout.

The results from this study have prompted us to consider several directions for future research. One future research direction is to replicate this study using different or more comprehensive samples, with the aim of supporting the results and pursuing findings that are generalizable. In addition, future research studies can explore specific contextual (e.g., setting, client populations, training experiences) and individual (e.g., moral identity [Aquino \& Reed, 2002], ethical and legal knowledge [Lambie et al., 2010], ethical and legal self-efficacy [Mullen, Lambie, \& Conley, 2014]) factors associated with counselors' experiences with ethical dilemmas (MAS scores; Reynolds, 2008). Researchers can also explore other constructs related to ethical dilemmas, 
such as moral intensity (May \& Pauli, 2002), moral disengagement (Detert, Treviño, \& Sweitzer, 2008), and moral awareness (Reynolds, 2006).

Researchers may want to consider examining the relationship that stress and burnout have on counselors' decision-making processes to see if counselors who are not experiencing stress or burnout make more effective decisions. In addition, scholars may want to consider an ethical decisionmaking model that incorporates the emotional response counselors incur during the experience of ethical situations, with an aim to support counselor well-being, similar to Blount and Mullen's (2015) clinical supervision model. In this light, researchers may want to explore mediating variables, such as coping style/strategy, self-efficacy, career-sustaining behaviors, and resiliency/grit. Another implication for future research is to explore the directional relationship in which stress contributes to burnout experienced by practicing counselors. Finally, because this study found a relationship between MAS scores and burnout and stress, future research could examine different methods or measures to explore the experience counselors have with ethical dilemmas.

In summary, in this study, we examined the relationship between counselors' experiences with ethical dilemmas and their stress and burnout. The findings indicated that higher occurrences of ethical issues were related to higher levels of stress and burnout. However, counselors' reflections on ethical issues were not related to stress and burnout. Nevertheless, there is a need for additional research concerning counselors' experiences resolving ethical dilemmas. Counselors should address the emotional costs of ethical dilemmas in their work to prevent undue stress and burnout. In addition, counselor educators and clinical supervisors can support students' and supervisees' awareness of their responses to ethical dilemmas.

\section{References}

American Counseling Association. (2014). ACA code of ethics. Alexandria, VA: Author.

Anderson, R. S., \& Levitt, D. H. (2015). Gender self-confidence and social influence: Impact on working alliance. Journal of Counseling E Development, 93, 280-288. doi:10.1002/jcad.12026

Aquino, K., \& Reed, A., II. (2002). The self-importance of moral identity. Journal of Personality and Social Psychology, 83, 1423-1440. doi:10.1037/0022-3514.83.6.1423

Barnett, V., \& Lewis, T. (1994). Outliers in statistical data (Vol. 3). New York, NY: Wiley.

Bentler, P. M., \& Chou, C. P. (1987). Practical issues in structural modeling. Sociological Methods and Research, 16, 78-117.

Blount, A., \& Mullen, P. R. (2015). Development of the Integrative Wellness Model: Supervising counselors-in-training. The Professional Counselor, 5, 100-113. doi:10.15241/ajb.5.1.100

Bodenhorn, N. (2006). Exploratory study of common and challenging ethical dilemmas experienced by professional school counselors. Professional School Counseling, 10, 195-202.

Byrne, B. M. (2010). Structural equation modeling with AMOS: Basic concepts, applications, and programming. New York, NY: Routledge.

Chao, R. C.-L. (2011). Managing stress and maintaining well-being: Social support, problemfocused coping, and avoidant coping. Journal of Counseling \& Development, 89, 338-348. doi:10.1002/j.1556-6678.2011.tb00098.x 
Chao, R. C. L. (2012). Racial/ethnic identity, gender-role attitudes, and multicultural counseling competence: The role of multicultural counseling training. Journal of Counseling $\mathcal{E}$ Development, 90, 35-44. doi:10.1111/j.1556-6676.2012.00006.x

Cohen, S., Kamarck, T., \& Mermelstein, R. (1983). A global measure of perceived stress. Journal of Health and Social Behavior, 24, 385-396.

Cordes, C. L., \& Dougherty, T. W. (1993). A review and an integration of research on job burnout. The Academy of Management Review, 18, 621-656. doi:10.2307/258593

Cottone, R. R., \& Claus, R. E. (2000). Ethical decision-making models: A review of the literature. Journal of Counseling \& Development, 78, 275-283.

Daire, A. P., Dominguez, V. N., Carlson, R. G., \& Case-Pease, J. (2014). Family Adjustment Measure: Scale construction and validation. Measurement and Evaluation in Counseling and Development, 47, 91-101. doi:10.1177/0748175614522270

Detert, J. R., Treviño, L. K., \& Sweitzer, V. L. (2008). Moral disengagement in ethical decisionmaking: A study of antecedents and outcomes. Journal of Applied Psychology, 93, 374-391. doi:10.1037/0021-9010.93.2.374

Dillman, D. A., Smyth, J. D., \& Christian, L. M. (2009). Internet, mail, and mixed-mode surveys: The tailored design method. Hoboken, NJ: Wiley.

Driskell, J. E., \& Salas, E. (1996). Stress and human performance. Mahwah, NJ: Erlbaum.

Dufrene, R. L., \& Glosoff, H. L. (2004). The Ethical Decision-Making Scale-Revised. Measurement and Evaluation in Counseling and Development, 37, 2-14.

Figley, C. R. (2002). Compassion fatigue: Psychotherapists' chronic lack of self-care. Journal of Clinical Psychology, 58, 1433-1441.

Folkman, S., Lazarus, R. S., Gruen, R. J., \& DeLongis, A. (1986). Appraisal, coping, health status, and psychological symptoms. Journal of Personality and Social Psychology, 50, 571-579.

Folkman, S., \& Moskowitz, J. T. (2004). Coping: Pitfalls and promise. Annual Review of Psychology, 55, 745-774. doi:10.1146/annurev.psych.55.090902.141456

Freudenberger, H. J. (1974). Staff burn out. Journal of Social Issues, 30, 159-165.

Freudenberger, H. J. (1986). The issues of staff burnout in therapeutic communities. Journal of Psychoactive Drugs, 18, 247-251.

Gall, M. D., Gall, J. P., \& Borg, W. R. (2007). Educational research: An introduction. Boston, MA: Pearson/Allyn \& Bacon.

Giacalone, R. A., Jurkiewicz, C. L., \& Promislo, M. (2016). Ethics and well-being: The paradoxical implications of individual differences in ethical orientation. Journal of Business Ethics, 137, 491-506. doi:10.1007/s10551-015-2558-8

Griffith, B. A., \& Frieden, G. (2000). Facilitating reflective thinking in counselor education. Counselor Education and Supervision, 40, 82-93.

Hair, J. F., Black, W. C., Babin, B. J., Anderson, R. E., \& Tatham, R. L. (2006). Multivariate data analysis. Upper Saddle River, NJ: Pearson.

Henderson, K. (2013). Mandated reporting of child abuse: Considerations and guidelines for mental health counselors. Journal of Mental Health Counseling, 35, 296-309. doi:10.17744/ mehc.35.4.x35610245863n034

Herlihy, B., \& Dufrene, R. L. (2011). Current and emerging ethical issues in counseling: A Delphi study of expert opinions. Counseling and Values, 56, 10-24. doi:10.1002/j.2161-007X.2011. tb01028.x

Hill, C. E., \& Lent, R. W. (2006). A narrative and meta-analytic review of helping skills training: Time to revive a dormant area of inquiry. Psychotherapy, 43, 154-172. doi:10.1037/00333204.43.2.154

Hu, L., \& Bentler, P. M. (1999). Cutoff criteria for fit indexes in covariance structure analysis: Conventional criteria versus new alternatives. Structural Equation Modeling, 6, 1-55.

Ivancevich, J. M., \& Matteson, M. T. (1980). Stress and work: A managerial perspective. Glenview, IL: Scott, Foresman.

Jackson, D. L. (2003). Revisiting sample size and number of parameter estimates: Some support for the N:q hypothesis. Structural Equation Modeling, 10, 128-141. doi:10.1207/ S15328007SEM1001_6 
Janis, I. L., \& Mann, L. (1977). Decision making: A psychological analysis of conflict, choice, and commitment. New York, NY: Free Press.

Jordan, N. A., Russell, L., Afousi, E., Chemel, T., McVicker, M., Robertson, J., \& Winek, J. (2014). The ethical use of social media in marriage and family therapy: Recommendations and future directions. The Family Journal, 22, 105-112. doi:10.1177/1066480713505064

Kaczmarek, P., Barclay, D., \& Smith, M. (1996). Systematic training in client documentation: Strategies for counselor educators. Counselor Education and Supervision, 36, 77-84.

Kenny, D. A., Kaniskan, B., \& McCoach, D. B. (2015). The performance of RMSEA in models with small degrees of freedom. Sociological Methods \& Research, 44, 486-507. doi:10.1177/0049124114543236

Kitchener, K. S. (2000). Foundations of ethical practice, research and teaching in psychology. Mahwah, NJ: Erlbaum.

Kline, R. B. (2011). Principles and practice of structural equation modeling. New York, NY: Guilford Press.

Kocet, M. M., \& Herlihy, B. J. (2014). Addressing value-based conflicts within the counseling relationship: A decision-making model. Journal of Counseling \& Development, 92, 180-186. doi:10.1002/j.1556-6676.2014.00146.x

Kramen-Kahn, B., \& Hansen, N. D. (1998). Rafting the rapids: Occupational hazards, rewards, and coping strategies of psychotherapists. Professional Psychology: Research and Practice, 29, 130-134.

Krejcie, R. V., \& Morgan, D. W. (1970). Determining sample size for research activities. Educational and Psychological Measurement, 30, 607-610.

Lambie, G. W. (2005). Child abuse and neglect: A practical guide for professional school counselors. Professional School Counseling, 8, 249-258.

Lambie, G. W., Hagedorn, W. B., \& Ieva, K. P. (2010). Social-cognitive development, ethical and legal knowledge, and ethical decision making of counselor education students. Counselor Education and Supervision, 49, 228-246. doi:10.1002/j.1556-6978.2010.tb00100.x

Lawson, G. (2007). Counselor wellness and impairment: A national survey. The Journal of Humanistic Counseling, 46, 20-34. doi:10.1002/j.2161-1939.2007.tb00023.x

Lawson, G., \& Myers, J. E. (2011). Wellness, professional quality of life, and careersustaining behaviors: What keeps us well? Journal of Counseling \& Development, 89, 163-171. doi:10.1002/j.1556-6678.2011.tb00074.x

Lawson, G., \& Venart, B. (2005). Preventing counselor impairment: Vulnerability, wellness, and resilience. In G. R. Walz \& R. K. Yep (Eds.), VISTAS: Compelling perspectives on counseling, 2005 (pp. 243-246). Alexandria, VA: American Counseling Association.

Lazarus, R. S. (2006). Stress and emotion: A new synthesis. New York, NY: Springer.

Lazarus, R. S., \& Cohen, J. B. (1977). Environmental stress. In I. Altman \& J. F. Wohlwill (Eds.), Human behavior and environment (Vol. 2). New York, NY: Plenum.

Lazarus, R. S., \& Folkman, S. (1984). Stress, appraisal, and coping. New York, NY: Springer.

Lee, S. M., Baker, C. R., Cho, S. H., Heckathorn, D. E., Holland, M. W., \& Newgent, R. A. (2007). Development and initial psychometrics of the Mental Health Professional Burnout Inventory. Measurement and Evaluation in Counseling and Development, 40, 142-154.

Lee, S. M., Cho, S. H., Kissinger, D., \& Ogle, N. T. (2010). A typology of burnout in professional counselors. Journal of Counseling \& Development, 88, 131-138. doi:10.1002/j.1556-6678.2010.tb00001.x

Lent, J., \& Schwartz, R. (2012). The impact of work setting, demographic characteristics, and personality factors related to burnout among professional counselors. Journal of Mental Health Counseling, 34, 355-372. doi:10.17744/mehc.34.4.e3k8u2k552515166

Levitt, D. H., \& Aligo, A. A. (2013). Moral orientation as a component of ethical decision making. Counseling and Values, 58, 195-204. doi:10.1002/j.2161-007X.2013.00033.x

Levitt, D. H., Farry, T. J., \& Mazzarella, J. R. (2015). Counselor ethical reasoning: Decision-making practice versus theory. Counseling and Values, 60, 84-99. doi:10.1002/j.2161-007X.2015.00062.x

Levitt, D. H., \& Hartwig Moorhead, H. J. (2013). Values and ethics in counseling: Real-life ethical decision making. New York, NY: Routledge.

Luke, M., Goodrich, K. M., \& Gilbride, D. D. (2013). Intercultural model of ethical decision making: Addressing worldview dilemmas in school counseling. Counseling and Values, 58, 177-194. doi:10.1002/j.2161-007X.2013.00032.x 
Maslach, C. (1976). Burned-out. Human Behavior, 5, 16-22.

Maslach, C. (2003). Burnout: The cost of caring. Cambridge, MA: Malor Books.

Maslach, C., \& Jackson, S. E. (1981). The measurement of experienced burnout. Journal of Occupational Behavior, 2, 99-113.

Maslach, C., Schaufeli, W. B., \& Leiter, M. P. (2001). Job burnout. Annual Review of Psychology, 52, 397-422.

May, D. R., \& Pauli, K. P. (2002). The role of moral intensity in ethical decision making: A review and investigation of moral recognition, evaluation, and intention. Business \& Society, 41, 84-117. doi:10.1177/0007650302041001006

McGrath, J. E. (1976). Stress and behavior in organizations. In M. D. Dunnette (Ed.), Handbook of industrial and organizational psychology (pp. 1351-1395). Chicago, IL: Rand McNally.

Merriman, J. (2015). Enhancing counselor supervision through compassion fatigue education. Journal of Counseling \& Development, 93, 370-378. doi:10.1002/jcad.12035

Mullen, P. R., Griffith, C., Greene, J. H., \& Lambie, G. W. (2014). Social media and professional school counselors: Ethical and legal considerations. Journal of School Counseling, 12. Retrieved from http:/ / jsc.montana.edu/articles/v12n8.pdf

Mullen, P. R., \& Gutierrez, D. (2016). Burnout, stress and direct student services among school counselors. The Professional Counselor, 6, 344-359. doi: 10.15241/pm.6.4.344

Mullen, P. R., Lambie, G. W., \& Conley, A. H. (2014). Development of the Ethical and Legal Issues in Counseling Self-Efficacy Scale. Measurement and Evaluation in Counseling and Development, 47, 62-78. doi:10.1177/0748175613513807

Mullen, P. R., Lambie, G. W., Griffith, C., \& Sherrell, R. (2016). School counselors' general self-efficacy, ethical and legal self-efficacy, and ethical and legal knowledge. Ethics $\mathcal{E}$ Behavior, 26, 415-430. doi:10.1080/10508422.2015.1033627

National Board for Certified Counselors. (2012). Code of ethics. Greensboro, NC: Author.

Nunnally, J. C. (1967). Psychometric theory. New York, NY: McGraw-Hill.

Osborne, J. W. (2012). Best practices in data cleaning: A complete guide to everything you need to do before and after collecting your data. Thousand Oaks, CA: Sage.

Osborne, J. W., \& Overbay, A. (2004). The power of outliers (and why researchers should always check for them). Practical Assessment, Research \& Evaluation, 9. Retrieved from http:/ / PAREonline.net/getvn.asp? $\mathrm{v}=9 \& \mathrm{n}=6$

Parker, D. F., \& DeCotiis, T. A. (1983). Organizational determinants of job stress. Organizational Behaviour \& Human Performance, 32, 160-177.

Pines, A., \& Maslach, C. (1978). Characteristics of staff burnout in mental health settings. Psychiatric Services, 29, 233-237.

Pompeo, A. M., \& Levitt, D. H. (2014). A path of counselor self-awareness. Counseling and Values, 59, 80-94. doi:10.1002/j.2161-007X.2014.00043.x

Puig, A., Baggs, A., Mixon, K., Park, Y. M., Kim, B. Y., \& Lee, S. M. (2012). Relationship between job burnout and personal wellness in mental health professionals. Journal of Employment Counseling, 49, 98-109. doi:10.1002/j.2161-1920.2012.00010.x

Remley, T. P., \& Herlihy, B. (2013). Ethical, legal, and professional issues in counseling (4th ed.). Upper Saddle River, NJ: Prentice Hall.

Reynolds, S. J. (2006). Moral awareness and ethical predispositions: Investigating the role of individual differences in the recognition of moral issues. Journal of Applied Psychology, 91, 233-243. doi:10.1037/0021-9010.91.1.233

Reynolds, S. J. (2008). Moral attentiveness: Who pays attention to the moral aspects of life? Journal of Applied Psychology, 93, 1027-1041. doi:10.1037/0021-9010.93.5.1027

Roach, L. F., \& Young, M. E. (2007). Do counselor education programs promote wellness in their students? Counselor Education and Supervision, 47, 29-45. doi:10.1002/j.1556-6978.2007. tb00036.x

Schaufeli, W. B., \& Enzmann, D. (1998). The burnout companion to study and practice: A critical analysis. London, England: Taylor \& Francis.

Schaufeli, W. B., Leiter, M. P., \& Maslach, C. (2009). Burnout: 35 years of research and practice. Career Development International, 14, 204-220. doi:10.1108/13620430910966406

Selye, H. (1936, July 4). A syndrome produced by diverse nocuous agents. Nature, 138, 32. 
Selye, H. (1980). The stress concept today. In I. L. Kutach \& L. B. Schlesinger (Eds.), Handbook on stress and anxiety: Contemporary knowledge, theory, and treatment (pp. 127-143). San Francisco, CA: Jossey-Bass.

Sink, C., \& Stroh, H. (2006). Practical significance: The use of effect sizes in school counseling research. Professional School Counseling, 9, 401-411. doi:10.5330/prsc.9.4.283746k664204023

Skovholt, T., \& Ronnestad, M. (1992). Themes in therapist and counselor development. Journal of Counseling \& Development, 70, 505-515.

Stamm, B. H. (2010). The concise ProQOL manual (2nd ed.). Pocatello, ID: Author.

Stebnicki, M. A. (2008). Empathy fatigue: Healing the mind, body, and spirit of professional counselors. New York, NY: Springer.

Stevens, J. P. (1992). Applied multivariate statistics for the social sciences (2nd ed.). Hillsdale, NJ: Erlbaum.

Stinchfield, T. A., Hill, N. R., \& Kleist, D. M. (2007). The reflective model of triadic supervision: Defining an emerging modality. Counselor Education and Supervision, 46, 172-183. doi:10.1002/j.1556-6978.2007.tb00023.x

Tabachnick, B. G., \& Fidell, L. S. (2007). Using multivariate statistics. Boston, MA: Pearson/ Allyn \& Bacon.

Thompson, I. A., Amatea, E. S., \& Thompson, E. S. (2014). Personal and contextual predictors of mental health counselors' compassion fatigue and burnout. Journal of Mental Health Counseling, 36, 58-77.

Venart, E., Vassos, S., \& Pitcher-Heft, H. (2007). What individual counselors can do to sustain wellness. The Journal of Humanistic Counseling, 46, 50-65. doi:10.1002/j.2161-1939.2007.tb00025.x

Von Wright, J. (1992). Reflections on reflection. Learning and Instruction, 2, 59-68.

Weston, R., \& Gore, P. A., Jr. (2006). A brief guide to structural equation modeling. The Counseling Psychologist, 34, 719-751. doi:10.1177/0011000006286345

Young, M. E. (2013). Learning the art of helping: Building blocks and techniques (5th ed.). Upper Saddle River, NJ: Merrill Prentice Hall.

Young, M. E., \& Lambie, G. W. (2007). Wellness in school and mental health systems: Organizational influences. The Journal of Humanistic Counseling, 46, 98-113. doi:10.1002/j.2161-1939.2007. tb00028.x 